$\xi=-1$

\title{
Integrating Infiltration Facility to Urban Road Drainage
}

\author{
Darrien Yau Seng Mah ${ }^{1 *}$, Tze Chiat $\mathrm{Ng}^{1}$, Frederik Josep Putuhena ${ }^{2}$ \\ ${ }^{1}$ Department of Civil Engineering, Faculty of Engineering, Universiti Malaysia Sarawak, 94300 Kota Samarahan, Sarawak, Malaysia \\ ${ }^{2}$ Program Teknik Sipil, Fakultas Teknik, Universitas Pancasila, Jakarta Selatan 12640, Indonesia \\ *Corresponding author E-mail: ysmah@unimas.my
}

\begin{abstract}
It is proposed to merge an infiltration facility to the conventional road curb system. Towards this end, a Storm Water Management Model (SWMM) is developed to explore the effectiveness of the proposed component at Riveria housing estate, Kota Samarahan, Sarawak. The findings show that the integration is effective in reducing peak runoff. The results indicate that a scenario of hollow infiltration trench achieves zero runoff, and a scenario of filled infiltration trench has a $43.6 \%$ reduction in runoff compared with existing road drainage condition. Furthermore, the hollow infiltration trench is found to be the best among all the given scenarios. The SWMM modelling results provide a tool to quantitatively measure the probable use of the proposed measures to improve the existing road drainage system.
\end{abstract}

Keywords: Impervious; MSMA; Road curb; Runoff; Stormwater; SWMM.

\section{Introduction}

Conventional road drainage system with road curb is scrutinized in this paper. Road curbs are the standard element for road sections, and they also form part of the urban drainage system [1]. They are meant to eliminate ponding of stormwater along the curb line. This system allows stormwater to directly discharge into a drain as shown in Figure 1. Therefore, the key issue to be highlighted here is that this rapid disposal of surface runoff to urban drains makes it an ineffective measure to mitigate floods. The disposal method has increased runoff volume and runoff velocity, exacerbated pollutant inputs, hydrologic disturbance and flash flooding [2]. Hence, a new approach is required to achieve the goal of stormwater control measures.

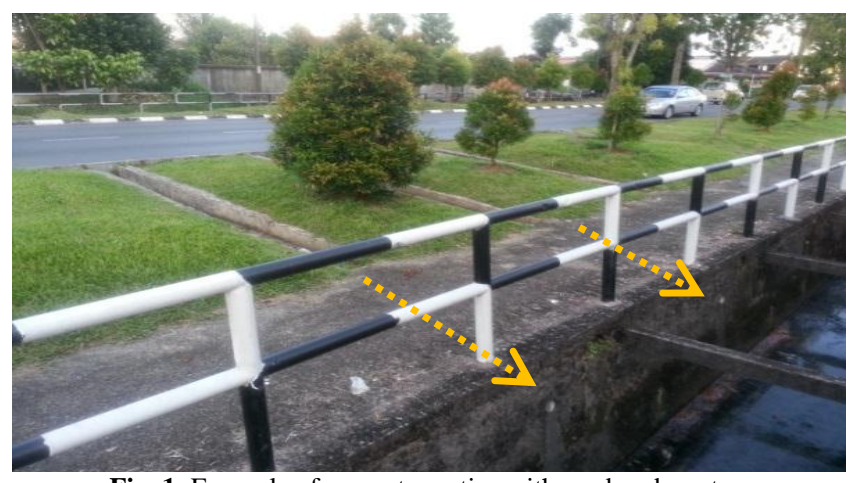

Fig. 1: Example of current practice with road curb system

Stormwater source control has become an alternative solution for urban stormwater management [3-4]. An approach to upgrade the existing road drainage system is by merging the road curb with infiltration trench. The trench could be used to overcome the limitations of the road curb system while the benefits of road curb are maintained. The cumulative benefits of this practice would help to maintain the natural water balance against urbanization. The inte- gration promotes groundwater recharge [5], enhances runoff quality naturally [6], and runoff reduction [7].

Infiltration trenches are generally installed near impermeable areas such as roofs and alongside roads to receive runoff [8-9]. Due to their simplicity, they usually perform well with other stormwater components [10]. Application of infiltration trenches does not require a wide land area [11], making them suitable to be merged with road curbs. The performance and efficiency of infiltration trenches in mitigating the impact of urbanization are evaluated using SWMM [12].

\section{Study Site}

Kota Samarahan, formerly known as Muara Tuang has a good road network connection to the adjacent Kuching City and other parts of Sarawak. This characteristic makes it suitable to be the central business district of Samarahan Division. Various educational, medical and research institutions are located within this region. Many projects such as the City Height, Uni Central, and Summer Mall have been rolling in, enabling Kota Samarahan to achieve the highest annual growth rate of 2.2 percent, the fastest in Sarawak (Chin, 2011). The Samarahan District Council covers a total area of 709.81 square kilometres. The population rose around 5 times from 46,966 in 2000 to 236,000 in 2010. Meanwhile, the growth of properties over ten years was observed to rise from 8,254 units in 2000 to 24,679 units in 2010 .

The irreversible impacts of urbanisation cannot be underestimated. The increase in impervious ground surface could exacerbate flooding disasters. Control of stormwater flooding is supposed to be the responsibility of urban cities. Therefore, Riveria housing estate, Kota Samarahan is chosen as the study site. The aerial plan and study site of Riveria is illustrated in Figures 2 and 3. Riveria housing estate is situated beside Kuap River that borders the Kuching City and Kota Samarahan. Particularly, Lorong 2 is examined in this study. This lorong has a curb and walkway system on one side 
of the road, which is good enough to be merged with an infiltration system under the walkway.

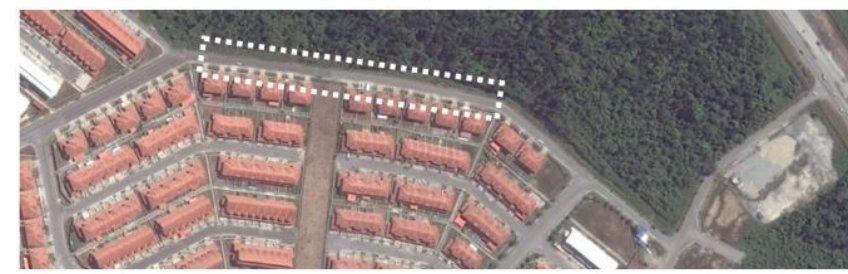

Fig. 2: Aerial view of Lorong 2, Riveria housing estate (http://www.wikimapia.org)

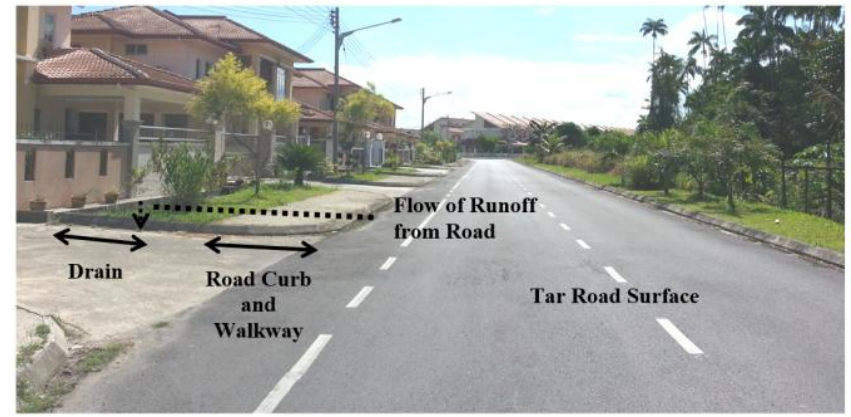

Fig. 3: Panoramic view of Lorong 2, Riveria housing estate

\section{Methods}

The design rainfall is based on synthetic storms. This approach utilises the average characteristics of previous rainfall events rather than the actual rainfall records. 15-minute, 10-year Average Recurrent Interval (ARI) design rainfall is chosen because the site is a localised residential development with small catchment areas. Taking into consideration of the existing stormwater outlets are $5 \mathrm{~m}$ apart and restriction of flow due to the outlets, a 15-minute storm duration is a conservative estimation for the runoff to flow from the furthest point of its associated catchment to drain.

The runoffs are computed based on two different equations. Rational Method is frequently used in computing stormwater flow from rainfall. The method often provides satisfactory results, especially for a small catchment area. Besides, Manning's equation is used to calculate the flow along an open channel. Both methods are used to manually calculate runoff from rainfall and along the open channel respectively, and then compared with the outputs of the SWMM model.

Assumptions made for sizing of trench are based on the MSMA requirements:

$$
\begin{array}{ll}
\text { Soil type } & =\text { Sandy loam } \\
\text { Infiltration capacity } & =0.0035 \mathrm{~m} / \mathrm{hr} \\
\text { Ground water level } \quad=2 \mathrm{~m} \text { (below ground surface) } & \multicolumn{2}{l}{\text { Time of concentration pre-development, tcs }=30 \text { minutes }} \\
\text { Time of concentration, tc } & =15 \text { minutes } \\
\text { Porosity of fill materials, } \mathrm{n} & =0.35 \\
\text { Maximum storage time, Ts } & =24 \text { hours } \\
\text { Effective filling time, Tf } & =2 \text { hours }
\end{array}
$$

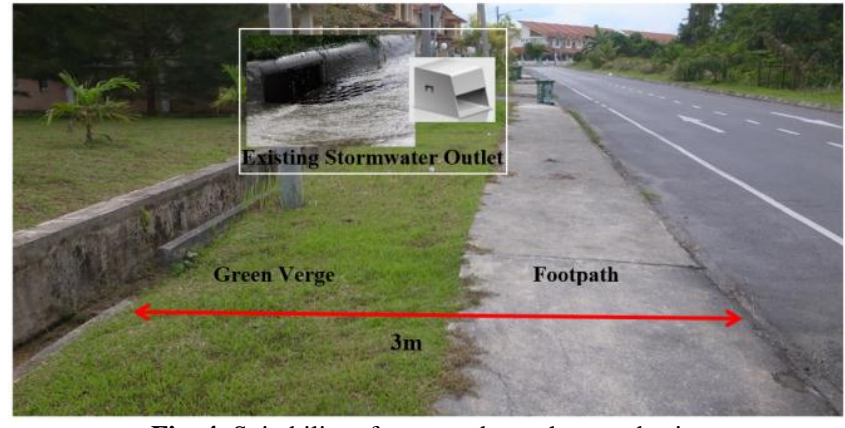

Fig. 4: Suitability of proposed trench at study site

SWMM is chosen for modelling the infiltration trench on the basis of runoff volume and peak flow. SWMM enables the simulation of runoff quantity from urban areas through sub-catchment areas that receive rainfall and generate runoff [13]. The routing of SWMM consists of transportation of stormwater through the catchments, pipes, channels, storage, and outlet. The capabilities of SWMM allow simulation of infiltration based on Horton or Green-Ampt equation. Therefore, SWMM is suitable to predict the behaviour and performance of the small-scale infiltration trench. Model buildings of SWMM are shown as follows:

Step 1: Loading of a background map (Figure 5) - To start building a drainage network, a background map is necessary. This map is to assist digitisation of nodes and other components.

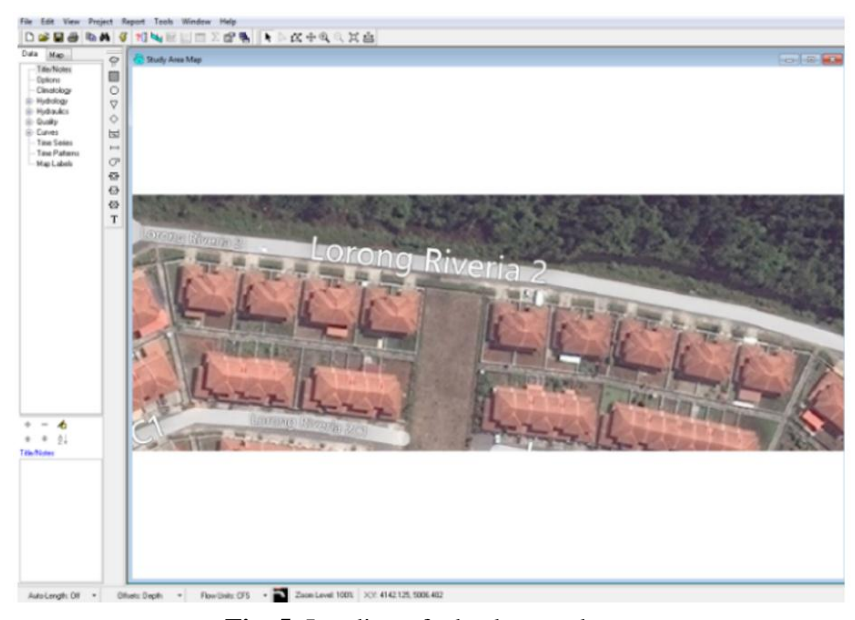

Fig. 5: Loading of a background map

Step 2: Input of rainfall data (Figure 6) - Calculated design rainfall data are keyed in to the model by using the component of Rain Gage ?.

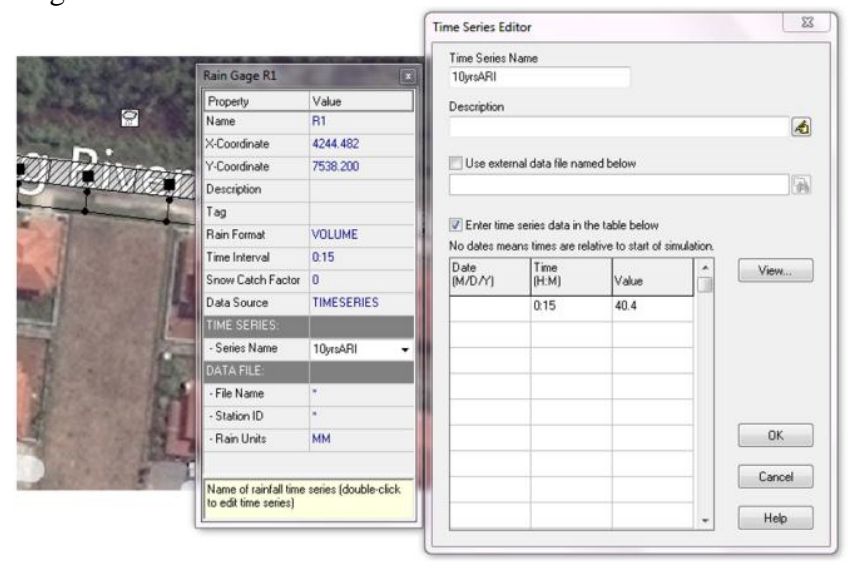

Fig. 6: Input of rainfall data

Sizing of the proposed infiltration trench is by "Best Economic Section" to derive a dimension of $1.5 \mathrm{~m}$ depth, $1.5 \mathrm{~m}$ width, and $5.0 \mathrm{~m}$ length. However, the effective depth is $1.2 \mathrm{~m}$ from the bottom of the trench. The remaining $0.3 \mathrm{~m}$ is to cater for the height of road curb's stormwater outlet. Hence, the infiltration trench is having an effective storage of $9 \mathrm{~m}^{3}$. The trench is able to fit under the green verge and footpath which have a total width of $3 \mathrm{~m}$ as shown in Figure 4. 
Step 3: Creation of catchments (Figure 7) - Rainfall befalls and intercepts by roofs and road surfaces. In this project, only road surfaces are considered. By using the component of catchment 圆, area of road surface is the parameter needed to compute runoff from rainfall. The total road surface area being modelled is 2200 $\mathrm{m}^{2}$.
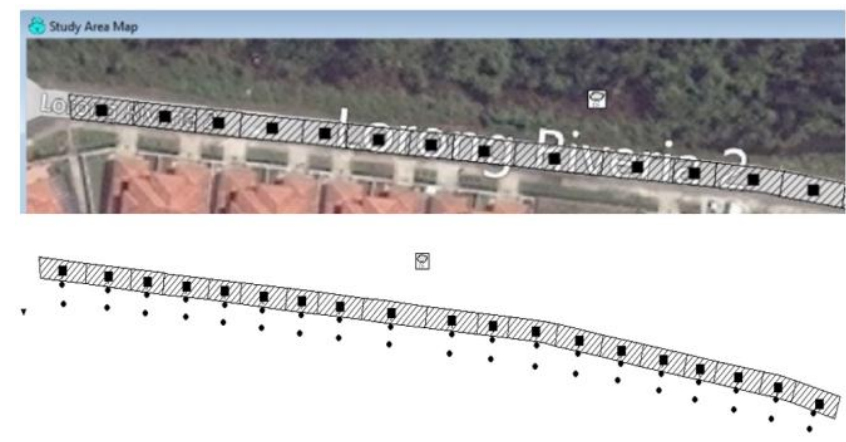

Fig. 7: Creation of catchments and junctions

Step 4: Creation of junctions (Figure 7) - The rainfall received by catchments is discharged through the respective junctions, and finally at the outfall. A junction is created alongside the road by using the component of junction $\square$. For the outfall, component $\nabla$ is used, and is located at the end of the flow path. Junctions are linked to the catchments.

Step 5: Creation of conduits (Figure 8) - Component of conduit $\square$ is used as the connection between junctions. Conduit serves to convey the water from point to point. Shape of conduit, maximum depth, length, and roughness are the parameters needed for simulation. The dimension of conduit is based on the existing drain ( $0.45 \mathrm{~m}$ depth $\times 1 \mathrm{~m}$ width). The roughness of concrete drain is 0.012 .

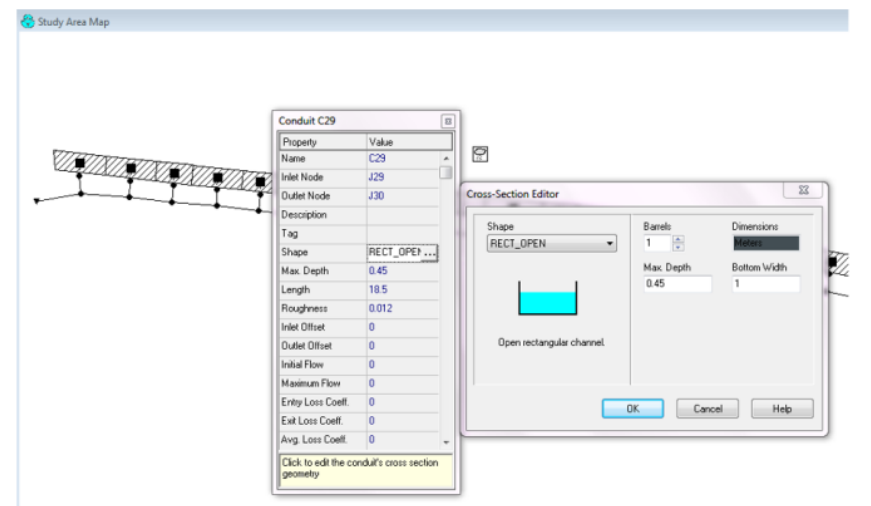

Fig. 8: Creation of conduits

Step 6: Model simulation - The model is run. The outputs of SWMM such as the runoff, storage volume, and infiltration losses can be obtained. The results from SWMM are double checked with manual calculation.

Step 7: Creation of storage unit (Figure 9) - Storage unit is added under the road curb system by using the component $\mathrm{G}$. Sizing of storage unit, where the parameters and assumptions are manipulated to achieve the best economic section. The proposed storage capacity is $9 \mathrm{~m} 3(1.2 \mathrm{~m}$ depth $\times 1.5 \mathrm{~m}$ width $\times 5 \mathrm{~m}$ length $)$.

Step 8: Creation of infiltration trench (Figure 10) - SWMM has a LID feature which allows simulation of infiltration trench. The proposed trench is backfilled with $0.9 \mathrm{~m}$ of porous material with a void ratio and hydraulic conductivity of 0.75 and $11 \mathrm{~mm} / \mathrm{hr}$ respectively. All the design values are based on the soil type and MSMA requirements.

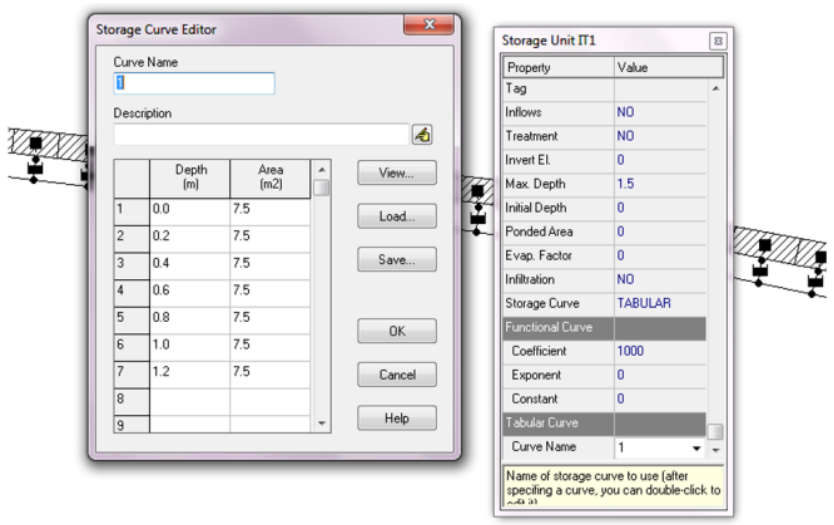

Fig. 9: Creation of storing unit (empty trench)

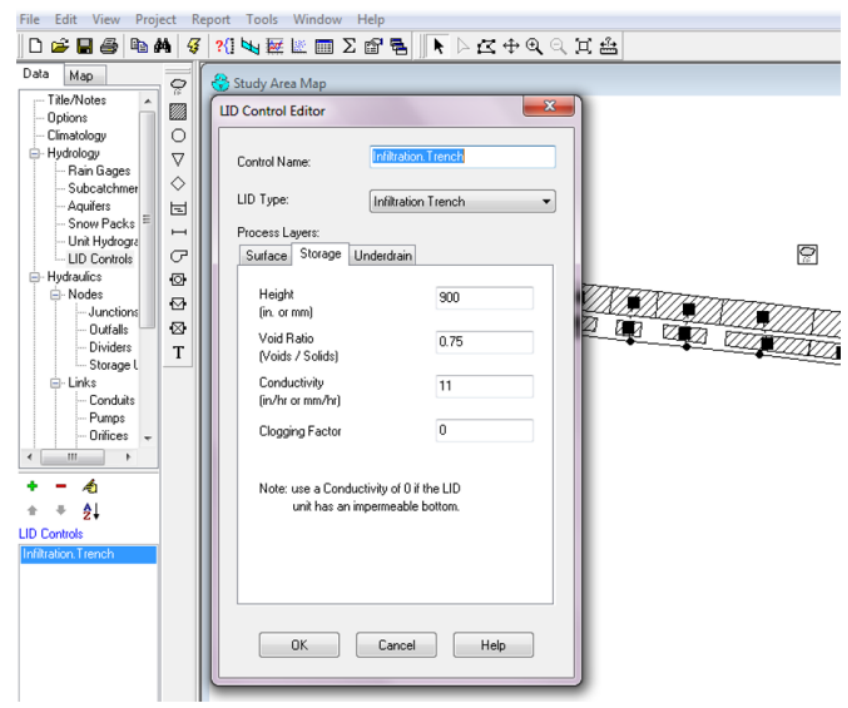

Fig. 10: Creation of infiltration trench with porous materials

\section{Results}

Three scenarios are presented here. The infiltration trench can manage the stormwater at the source and eventually enhance the groundwater recharge and reduce peak flow.

Scenario 1 is basically the existing condition of the drainage system (Figure 11). The rainfall is directly discharged into the drain without any use of stormwater component. The SWMM is used to simulate the runoff along the drain and eventually discharged at an outfall.
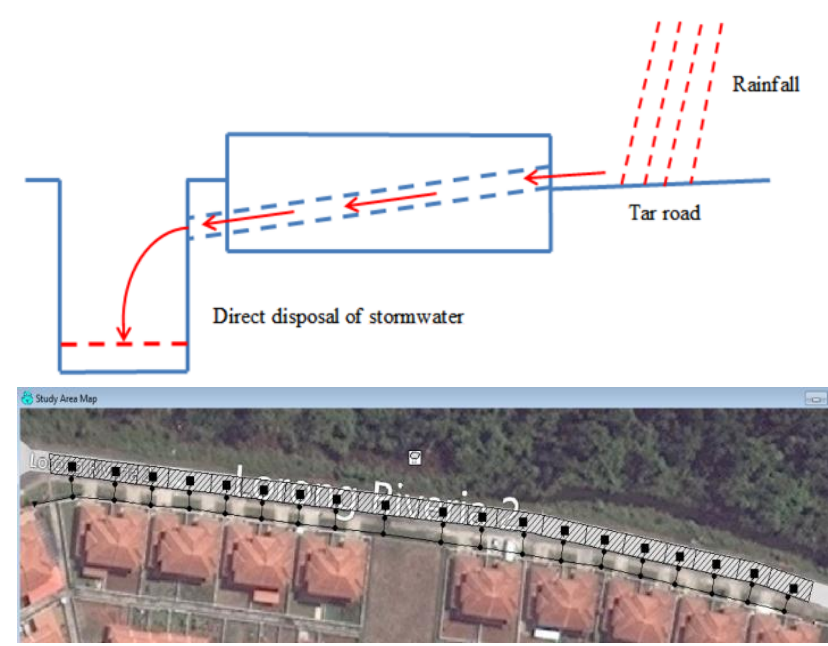

Fig. 11: Existing drainage system and modelling of Scenario 1 in SWMM 
A trench is introduced into the system. The proposed trench is to be placed under the curb. The trench is proposed as an empty trench (Figure 12) with a dimension of $1.5 \mathrm{~m}$ depth, $1.5 \mathrm{~m}$ wide, and $5.0 \mathrm{~m}$ length, to maximise the storage capacity. The outflow pipe has an invert level of $1.2 \mathrm{~m}$ and the trench is able to store 9 $\mathrm{m}^{3}(1.2 \mathrm{~m} \times 1.5 \mathrm{~m} \times 5.0 \mathrm{~m})$ of stormwater. The rainfall is disposed into the drain only if the trench reaches its maximum storage capacity. SWMM is used to simulate the runoff at drainage outfall. Storage units are added in the model compared to none of those structures in previous scenario.

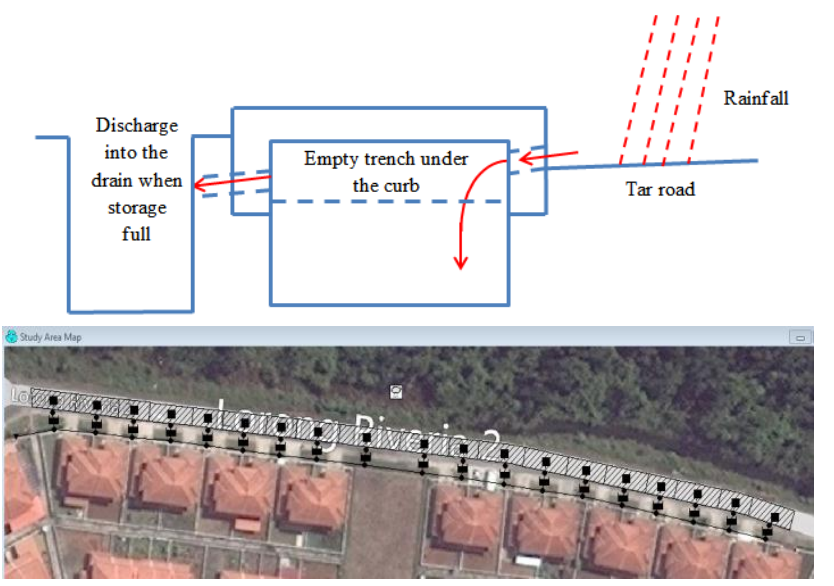

Fig. 12: Hollow infiltration trench and modelling of Scenario 2 in SWMM

Scenario 3 is a continuation from Scenario 2. The difference is that Scenario 3 has a proposed infiltration trench backfilled with porous materials (Figure 13), which reduces its storage capacity but enhances the infiltration rate. The simulation of Scenario 3 uses the built-in LID control feature provided in SWMM. In this case, the LID component serves as a catchment and receives additional rainfall. SWMM is used to simulate the runoff at the outfall and the losses due to infiltration.

In this scenario, infiltration process is imposed in the trench, based on Horton's equation. Sandy loam with high hydraulic conductivity is proposed in this scenario to maximise the infiltration losses into the soil layer. The assumption made is that the existing soil is excavated deeper than the proposed depth $(1.5 \mathrm{~m})$ and backfilled with the proposed soil.
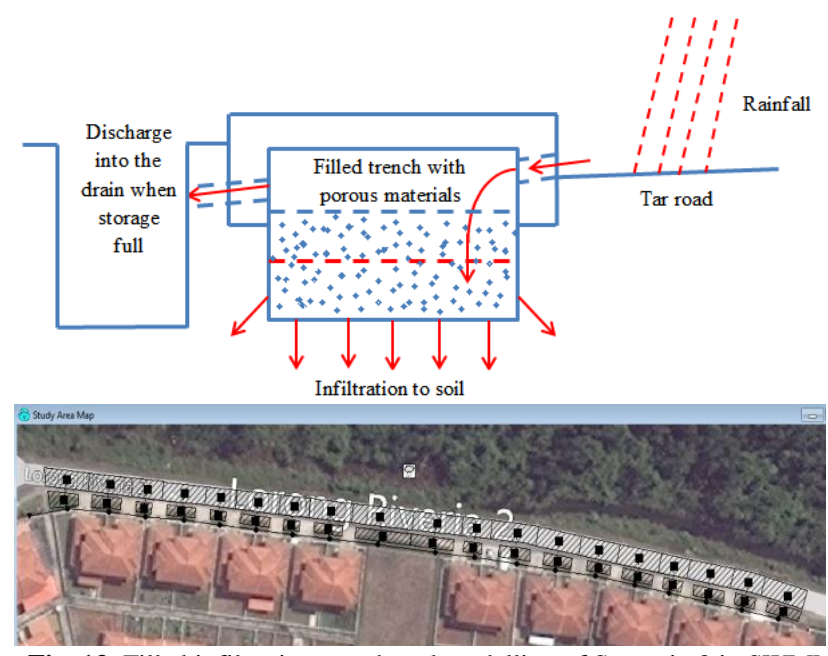

Fig. 13: Filled infiltration trench and modelling of Scenario 3 in SWMM

\section{Discussion}

The results of SWMM modelling are described by comparing the existing scenario with two proposed scenarios. A 15-minute, 10year ARI design rainfall is simulated for all scenarios. The design rainfall is estimated at $161.6 \mathrm{~mm} / \mathrm{hr}$ for Kota Samarahan. Runoff generated from the road catchments is drained through nodes and conduits respectively, and is discharged through an outfall.

SWMM simulation shows the efficiency of the proposed measures in terms of runoff rate. These runoffs flow from road surfaces before going through the invented scenarios. The peak runoffs at outfall for Scenarios 1, 2, and 3 are estimated at $0.0427 \mathrm{~m}^{3} / \mathrm{s}$, $0.0000 \mathrm{~m}^{3} / \mathrm{s}$, and $0.0241 \mathrm{~m}^{3} / \mathrm{s}$ respectively (Figure 14). For Scenario 2, the hollow trench captures fully the runoff. On the other hand, Scenario 3 reduces the runoff by $43.6 \%$ compared to Scenario 1 . The infiltration trench takes up approximately half of the runoff from the impervious road area. This result is theoretically parallel with findings of [14] that infiltration trenches are capable of reducing the peak and volume of runoff.

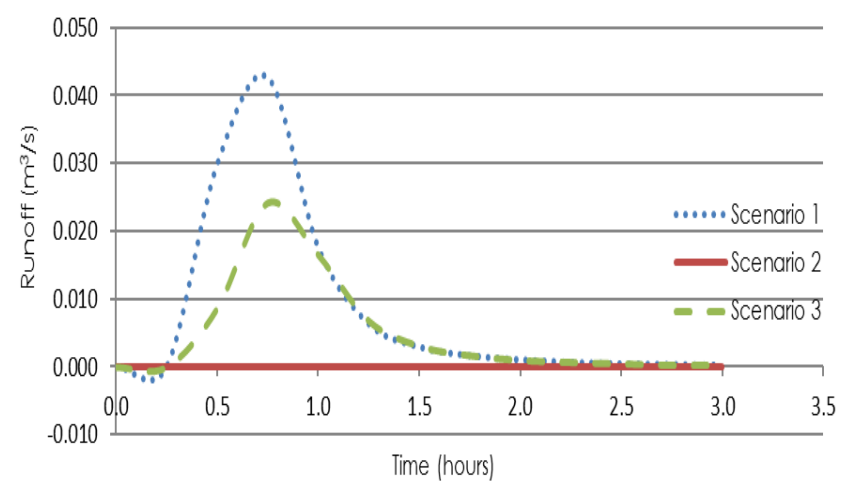

Fig. 14: Runoff hydrographs for different Scenarios

Scenario 2 has a storage capability that differentiates it from other scenarios. The volume of runoff stored in the trench is compared based on the consistency of volume filled up. On an average, the volume of runoff stored is approximately $4 \mathrm{~m}^{3}$. For a 10-year ARI design rainfall, the trench is considered sufficient in the context of the designed capability. The volume decreases with time after receiving the peak runoff as water infiltrates into the ground.

Although both scenarios allow water to infiltrate, Scenario 2 is preferred for long-term performance. Scenario 3 is no longer effective in reducing runoff if the maximum storage capacity is reached. The proposed storage capacity in Scenario 2 is expected to fill up faster, especially in extreme rainfall events.

\section{Conclusion}

In this study, simulation of infiltration trenches is presented by using SWMM 5.0. The trenches are found to fit into the limited land spaces of study area. The proposed scenarios have been compared with the existing scenario. It is found to slow down surface runoff and allows natural infiltration processes to take place. On the basis of a short-term simulation of 10-year ARI design rainfall, the performance and the effectiveness of both proposed measures are capable of reducing the risk of flash floods. Therefore, both succeed in their stated stormwater management goals.

Scenario 2 is found to be the best among all scenarios due to its sustainable performance. Effectiveness of the component in reducing surface runoff is significant. Such application would be of great importance to urban centres in the future as extreme weathers are happening more frequently.

\section{Acknowledgement}

This project was funded by Universiti Malaysia Sarawak via Special Top Down Grant F02/SpTDG/1440/16/3. 


\section{References}

[1] United States Environmental Protection Agency (USEPA) (2006), Eliminating Curbs and Gutters. Retrieve July 9, 2013 from http://cfpub.epa.gov/npdes/stormwater/menuofbmps/index.cfm)

[2] Loftin H, Tuttle R, Monde M, Calmbacher J, Frevert DK (2010), Using LID retrofits for flood control and to achieve receiving water quality standards. In: Innovations in Watershed Management under Land Use and Climate Change. Proceedings of the 2010 Watershed Management Conference by American Society of Civil Engineers (ASCE), Madison, Wisconsin, USA, 23-27 August. 828-837.

[3] De Souza VCB, Goldenfum JA, Barround S (2002), An experimental and numerical study of infiltration trenches in urban runoff control. Proceedings of 9th International Conference on Urban Drainage: Global Solutions for Urban Drainage, Portland, Ore.

[4] Zakaria A, Ab. Ghani A, Abdullah R, Sidek LM, Kassim AH, Ainan A (2004), MSMA - A new urban stormwater management manual for Malaysia. 6th International Conference on Hydroscience and Engineering (ICHE-2004), Brisbane, Australia, May 30 - June 3.

[5] Chahar BR, Graillot D, Gaur S (2011) Storm-water management through infiltration trenches. Journal of Irrigation and Drainage Engineering 138(3), 274-281.

[6] Nilsson E, Stigsson A (2012), Pollutant Removal Efficiencies and Flow Detention of Infiltration Trenches. Master of Science Thesis, Department of Civil and Environmental Engineering, Chalmers University of Technology.

[7] Fujita S (2014), Infiltration structures in Tokyo. Water Science \& Technology 30(1), 33-41

[8] Schueler TR (1987), Controlling Urban Runoff: A Practical Manual for Planning and Designing Urban PMPs. Metropolitan Washington Council of Government, Washington, DC.

[9] Sieker F (1998), On-site stormwater management as an alternative to conventional sewer systems: a new concept spreading in Germany. Water Science and Technology 38(10), 65-71.

[10] Lee JM, Hyun KH, Choi JS, Yoon YJ, Geronimo FKF (2012), Flood reduction analysis on watershed of LID design demonstration district using SWMM5. Desalination and Water Treatment 38(1-3), 255-261.

[11] Jia H, Lu Y, Shaw LY, Chen Y (2012), Planning of LID-BMPs for urban runoff control: the case of Beijing Olympic Village. Separation and Purification Technology 84, 112-119.

[12] Alamailes A, Walton J, Sandoval P, Woocay A, Broesicke O (2014) Sustainable house-scale passive rainwater capture landscape in the Desert Southwest. Journal of Green Building 9(1), 113-129.

[13] Rossman LA (2010), Storm Water Management Model User's Manual, Version 5.0. National Risk Management Research Laboratory, Office of Research and Development, US Environmental Protection Agency.

[14] Beecham SC (2003), Water sensitive urban design: a technological assessment. Waterfall, Journal of the Stormwater Industry Association, Issue 17, Summer, 5-12. 